\title{
Azerbaycan Propolislerinin Fenolik Madde İçerikleri ve Kalite Açısından Değerlendirilmesi
}

\author{
$\odot$ Rashad Sariyev ${ }^{\star 1}$, $\odot$ Meltem Çayci ${ }^{1}, \oplus$ Hasan Hüseyin Oruç ${ }^{2}$
}

1 Bursa Uludağ Üniversitesi, Veteriner Fakültesi, Farmakoloji ve Toksikoloji Anabilim Dalı, Nilüfer, Bursa

2 Bursa Uludağ Üniversitesi, Veteriner Fakültesi, Farmakoloji ve Toksikoloji Anabilim Dalı, Nilüfer, Bursa

Received 14.06.2019 Accepted 04.09.2019

\begin{abstract}
Özet
Propolisin antioksidan, antimikrobiyal, immunostimülan ve antitümöral gibi biyolojik etkileri, içeriğindeki fenolik bileşiklerden kaynaklanır. Fenolik bileşiklerin nitel ve nicel analizleri propolisin kalitesini değerlendirmede çok önemlidir. Bu çalışmanın amacı, Azerbaycan’dan toplanan ham propolislerde, faydalı biyolojik özellikleri bilinen fenolik bileşiklerin nitel ve nicel olarak analizini yapmak ve sonuçları değerlendirmektir. Propolis örnekleri Azerbaycan’ı 5 ilinde bulunan, toplam 14 farklı arılıktan, kovanın farklı kısımlarından kazınarak, 2018 sonbahar mevsiminde topland. Toplam 14 ham propolis örneğinde, 17 hedef fenolik bileşiğin (flavonoid ve fenolik asitler) HPLC-DAD sistemiyle analizi yapıldı. Analizi yapılan tüm örneklerde epigallokateşin gallat, kafeik asit, ferulik asit ve isoferulik asit tespit edildi. Propolisin toplandığı şehirlere göre propolis örnekleri arasında fenolik bileşikler ve miktarları bakından farklılıklar olduğu görüldü. Bu çalışmada Azerbaycan propolisinin kalitesinin genel olarak iyi olduğu ve fenolik madde içeriğinin Avrupa ve Türkiye'deki propolislere benzer olduğu tespit edilmiştir.
\end{abstract}

Anahtar kelimeler: Azerbaycan, propolis, fenolik bileşikler, HPLC-DAD.

\begin{abstract}
Evaluation of Content of Phenolic Compounds and Quality of Azerbaijan Propolis

Biological effects of propolis such as antioxidant, antimicrobial, immunostimulan and antitumoral due to its phenolic compounds. Qualitative and quantitative analysis of phenolic compounds is very important in evaluating the quality of propolis. The aim of this study is to make a qualitative and quantitative analysis of phenolic compounds with known beneficial biological properties in raw propolis collected from Azerbaijan and to evaluate the results. Propolis samples were collected by scraping from the hives from 14 different apiaries located in five Azerbaijan provinces autumn of 2018. Seventeen target phenolic compounds (flavonoid and phenolic acids) were analysed in 14 raw propolis samples by HPLC-DAD system. Epigallocatechin gallate, caffeic acid, ferulic acid and isoferulic acid were detected in all analysed samples. Differences were determined for target phenolic compounds and levels for collected provinces. Quality of Azerbaijan propolis samples were generally good and content of phenolic compounds were similar with Europe and Turkish propolis.
\end{abstract}

Keywords: Azerbaijan, propolis, phenolic compounds, HPLC-DAD.

\section{Giriş}

Propolis bal, polen, arı sütü ve balmumu gibi bir arı ürünüdür. Bal arıları, propolisi bitki ve ağaçların sürgün, çatlak gibi bazı kısımlarında bulunan reçine ve salgıları toplayıp, balmumu ve kendi enzimlerini de katarak oluşturur. ${ }^{1}$ Propolis sar1-yeşilden, koyu kahverengine kadar değişen renklerde, soğukta sert ve kırılgan, sıcakta 
ise yumuşak ve yapışkan bir yapıya sahiptir. ${ }^{2}$ Bal arıları, propolisi başlıca arı kolonisini tehdit edebilecek zararlı patojen mikroorganizmalara karşı kovan sağlığını korumak için kullanır.3 Bunun yanı sıra kovandaki bazı kısımların onarılmasında, kovana giren işgalcileri öldürdükten sonra kokuşmaması için mumyalanmasında, kovanın nemlilik oranı ve iç ısısının korunmasında kullanır. Propolisin arılar tarafından farklı amaçlar için kullanabilmesinin sebebi içeriğinin biyolojik olarak aktif bileşiklerle zengin olması ve yapışkanlığı sayesindedir ${ }^{3-4}$

Propolisin insanlar tarafından kullanımı bal kadar eskidir. Bilinen kayıtlara göre eski Mısırlılar, Persler ve Romalılar tarafından propolisin tedavi edici özelliği bilinmektedir ve birçok hastalığın tedavisi ve hafifletilmesinde kullanılmıştır. ${ }^{5}$ Gönümüzde ise propolisin antibakteriyel, antifungal, antiviral, antienflamatuar, antiülser, lokal anestezik, hepatoprotektif, antitümöral ve immün sistemi uyarıcı etkilere sahip olması sebebiyle apiterapi, sağlıklı beslenme ve biyokozmetik alanında kullanımı yaygınlaşmıştır. ${ }^{6-7}$ Propolisin biyolojik özelliği içeriğinde bulundurduğu kimyasal bileşenlerden kaynaklanır. Bu bileşenler de mevsime, rakıma, coğrafyaya ve bitki kaynağına göre değişiklik göstermektedir. ${ }^{1,8-11}$ Propolis 300'den fazla kimyasal bileşen içermektedir. Bu maddeler fenolik bileşikler ve esterleri, alkoller, aldehitler, ketonlar, terpenler, kumarinler, steroidler, aminoasitler, vitaminler, mineraller, yağ asidi ve enzimlerdir. Fenolik bileşiklerden olan flavonoidler ve fenolik asitlerin propolisin ana kimyasal bileşenleri olduğu ve propolise biyolojik özellikler kazandırdığı bilinmektedir. ${ }^{2,12-14}$ Propolisin içeriği ve biyolojik özellikleri ile ilgili farklı ülkelerde pek çok çalışma bulunmaktadır. ${ }^{15-21}$ Azerbaycan propolisinin içerdiği fenolik bileşiklerle ilgili bazı çalışmalar bulunmaktadır. ${ }^{13,22}$ Ancak yapılan bu çalışmaların sayısı, numune sayısı ve araştırılan fenolik bileşikler ve kalite değerlendirmesi yönüyle daha fazla çalışmaya ihtiyaç duyulmaktadır.

Propoliste bulunan başlıca fenolik bileşikler, biyolojik ve farmakolojik etkilerini detaylandırdığımızda; galangin antibakteriyel, antitümöral, antiviral, antienflamatuar ${ }^{23}$ ve antioksidan ${ }^{9}$ etkilere sahiptir. Pinosembrinin (pinocembrin) antioksidan ve antiapoptotik etkileri bulunmaktadır. ${ }^{24}$ Apigenin antibakteriyel, antiviral, antiülser ${ }^{25}$ ve antitümöral ${ }^{26}$ etkilidir. Naringenin antioksidan, antitümöral ve antienflamatuar, ${ }^{27-28}$ kuarsetin (quersetin) antibakteriyel, antitümöral, antiviral, antienflamatuar ${ }^{25}$ etkilere sahiptir. Kaemferol (kaempferol) ise antioksidan, antienflamatuar, antitümöral, kardioprotektif, nöroprotektif, antidiabetik, analjezik ve antialerjik etkilidir. ${ }^{29}$ Kafeik asit (caffeic acid) antibakteriyel, antiviral, antioksidan, ${ }^{25}$ antitümöral ${ }^{30}$ ve antiülser ${ }^{15}$ etkiye sahiptir. Kafeik asit fenetil esterin (caffeic acid phenylethyl ester, CAPE) antibakteriyel, antioksi- dan, antienflamatuar, antitümöral, antiviral ve immunomodülatör etkileri bulunmaktadır. ${ }^{23,31-32}$ Ferulik asitin (ferulic acid) antitümöral ve antioksidan etkileri vardır. ${ }^{33}$ Sinnamik asit (cinnamic acid) antibakteriyel, antitümöral ve antiülser etkilidir. ${ }^{15,34}$ Gallik asitin (gallic acid) prostat kanserine karşı etkili olduğu bulunmuştur. ${ }^{35}$

Bu çalışmada, Azerbaycan ham propolislerinde, yukarıda belirtilen ve faydalı etkileri bilinen fenolik bileşiklerin nitel ve nicel olarak, HPLC-DAD sistemi ile analiz edilmesi ve kalitesi hakkında bilgi sahibi olunması amaçlanmıştır. Ayrıca Azerbaycan'da arıcılar, özellikle de bilim insanları ve halk bal dışında diğer arı ürünleri ve propolisi yeterince bilmemektedir. Bu nedenle bu çalışma Azerbaycan'da propolis çalışmaları ve propolisin tanınmasına da katkı sunacaktır.

\section{Materyal ve Metot}

\section{Kimyasallar ve çözücüler}

Galangin, quercetin (hydrate), kaempferol, gallic acid, naringenin ( \pm ), pinocembrin, apigenin, cinnamic acid (trans), caffeic acid, CAPE, ferulic acid (trans), Sigma-Aldrich'ten (St Louis, MO, ABD); chrysin, isoferulic acid (trans), (-)- epigallocatechin gallate (EGKG), methyl syringate, 3,4-dimethoxycinnamic acid, chalcone (trans) Santa Cruz Biotechnology'den (Dallas, ABD) satın alındı. HPLC kalitesinde metanol, asetonitril ve analiz kalitesinde formik asit ve etanol Merck'ten (Darmstadt, Germany) temin edildi. Analizde kullanılan su ELGA LabWater, Purelab flex (Marlow, Buckinghamshire, UK) sistemi kullanılarak aritild.

\section{Örnekler}

Ham propolis örnekleri Azerbaycan da bulunan Gence (2), Şemkir (6), Kazah (2), Gedebey (2) ve Kebele (2) illerinde, 14 farklı arılıktan, kovanın farklı kısımlarından kazınarak, 2018 yılı eylül ayında toplandı. Numunelerin toplandığ 1 alanlar Şekil l'de gösterilmiştir.

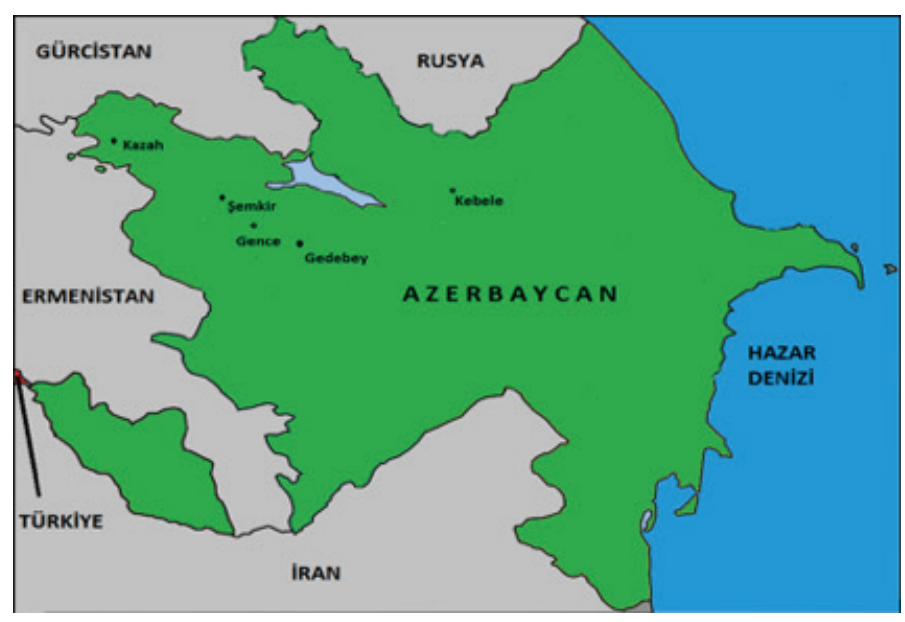

Şekil 1. Azerbaycan'da propolis örneklerin toplandığ şehirler. 


\section{Ekstraksiyon yöntemi}

Propolis ekstraksiyonunda başlıca Erdoğan ve ark. ${ }^{36}$ ve Trusheva ve ark. ${ }^{37}$ uygulamış oldukları metotlar kullanıldı. Ham propolis numuneleri $-20{ }^{\circ} \mathrm{C}$ de en az 24 saat donduruldu, sonrasında ham propolisler (30-50 g) küçük parçalara bölündü ve bir kahve değirmeni (DeLonghi KG 49) kullanılarak ince bir şekilde toz haline getirildi. Toz haline getirilen propolis numunelerinden 2 g ekstraksiyon için tartıldı ve \%70'lik etanol ilave edilerek karıştırıldı. Her propolis numunesine 1:9 oranında \%70'lik etil alkol ilave edildi. Bu nedenle $2 \mathrm{~g}$ propolis $50 \mathrm{ml}$ 'lik erlenmayer içerisine alındı üzerine \%70'lik (etanol/su, v/v) $18 \mathrm{ml}$ etil alkol ilave edildi; sonrasında 15 dakika ultrasona tabi tutuldu (Bandelin, Sonorex, RK 100). Daha sonra örnek kapalı karıştırıcıda $55^{\circ} \mathrm{C}$ 'de, 3 saat karıştırıldı ve sonra tekrar 15 dakika ultrasonik banyoda karıştırıldı (Bandelin, Sonorex, RK 100). Karıştırıldıktan sonra, önce adi süzgeç kağıdı ve sonra ise Watman süzgeç kağıdından (Watman No: 1, Buckinghamshire, UK) süzülerek propolis içerisinde bulunan yabancı cisimler uzaklaştırıldı. Elde edilen filtrat HPLC analizi için polivinil diflorür (PVDF) şırınga filtresinden (Millipore Millex-HV, $0.45 \mu \mathrm{m}$ ) geçirilerek 1.5 ml'lik viallere alınd 1 ve otosampler ile $5 \mu$ l HPLC-DAD sistemine enjeksiyonu yapıldı. Propolis numunelerinin ekstraksiyon işlemi ve HPLC-DAD okuma işlemleri, Uludağ Üniversitesi Veteriner Fakültesi, Farmakoloji ve Toksikoloji Anabilim Dalı laboratuvarında gerçekleştirildi.

\section{HPLC-DAD analizi}

Analizler başlica Pellati ve ark. ${ }^{38}$ bildirdiği metoda göre yapıldı. Kromatografik ayrıştırma, $1 \mathrm{ml} / \mathrm{dk}$ akış hızında Inertsil $^{\circ}$ ODS-3 (5 $\mu \mathrm{m}, 4.6 \times 150 \mathrm{~mm}$, Tokyo, Japan) kolon kullanılarak gerçekleştirildi. Taşıyıcı solvent olarak mobil faz A (\% 0.1 formik asit ve deiyonize su, v/v) ve mobil faz B (asetonitril) kullanıldı. Analiz $30^{\circ} \mathrm{C}$ kolon 1sisinda, $5 \mu \mathrm{l}$ örnek enjeksiyonu ile ve $270 \mathrm{~nm}$ dalga boyunda ve gradient sistemle yapild. Gradient sistem bilgileri Tablo 1'de verTablo 1. Mobil faz akış bilgileri.

\begin{tabular}{|l|l|l|}
\hline Zaman (dakika) & Mobil faz A (\%) & Mobil faz B (\%) \\
\hline 0.01 & Başlangı̨ & \\
\hline 0.02 & 90 & 10 \\
\hline 3 & 75 & 25 \\
\hline 15 & 70 & 30 \\
\hline 60 & 50 & 50 \\
\hline 70 & 40 & 60 \\
\hline 80 & 10 & 90 \\
\hline 85 & 40 & 60 \\
\hline 90 & 75 & 25 \\
\hline 95 & 90 & 10 \\
\hline 104 & Durdurma & \\
\hline
\end{tabular}

ilmiştir.

Fenolik bileşiklerin stok çözeltileri $1 \mathrm{mg} / \mathrm{ml}$ olacak şekilde metanolde hazırlandı. Fenolik bileşiklerin standartları HPLC sistemine enjeksiyon yapılarak ana pikler, geliş zamanları ve spektrumları tespit edildi. Kalibrasyon eğrisi oluşturmak için stok çözeltiler metanol ile dilüe edilerek 3, 6, 12, 24 ve $48 \mu \mathrm{g} / \mathrm{mL}$ konsantrasyonlarda 5 farklı ara çözelti hazırlandı. Kalibrasyon eğrisinin korelasyon katsayıları $\left(\mathrm{R}^{2}\right)$, fenolik bileşiğe bağlı olarak 0.967 ile 0.999 aralığında bulundu. Fenolik bileşiklerin limit of quantification (LOQ) değeri 2.46 ile $7.56 \mu \mathrm{g} / \mathrm{mL}$ arasında ve limit of detection (LOD) değeri 0.82 ile $3.36 \mu \mathrm{g} / \mathrm{mL}$ arasında tespit edildi.

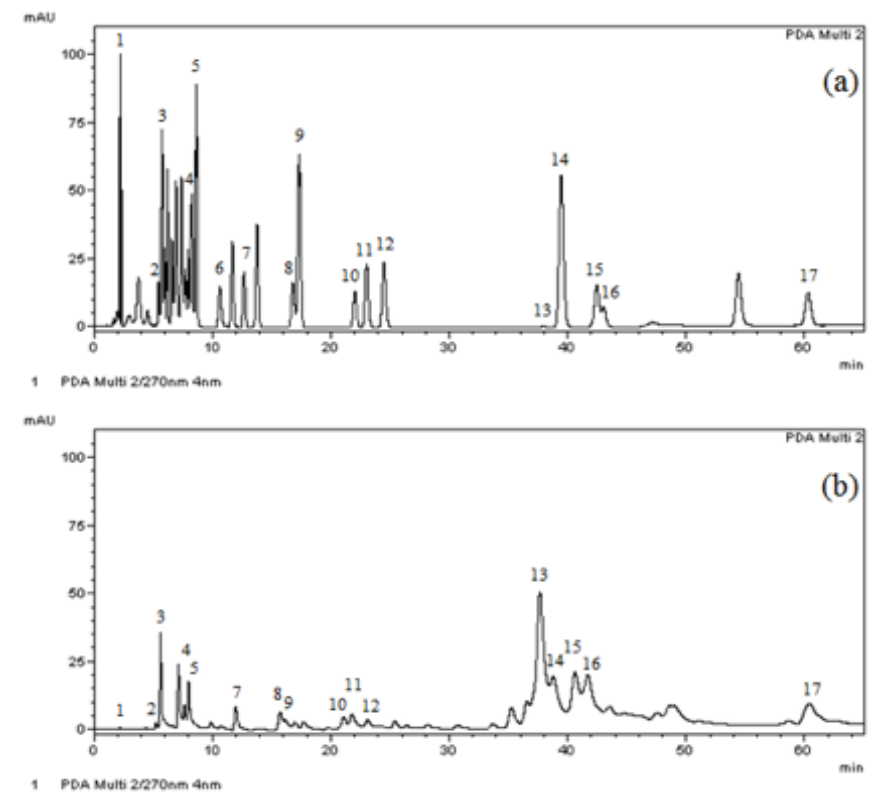

Şekil 2. Fenolik bileşiklerin standart kromotogramı (a) ve Kebele I numunesinin kromotogramı (b).

1: Gallik asit; 2: Epigallokateşin gallat; 3: Kafeik asit; 4: Ferulikasit; 5: İsoferulik asit; 6: Metilsiringate; 7: 3,4-Dimetoksisinamik asit;

8: Kuersetin; 9: Sinnamik asit; 10: Naringenin; 11: Apigenin; 12: Kaemferol; 13: Krisin; 14: Pinosembrin; 15: Galangin; 16: Kafeik asit fenetil ester; 17: Kalkon.

\section{İstatistiksel yöntem}

İstatistiksel analizler SPSS (Version 20.0) (SPSS Inc., Chicago, IL, USA) program ve Kruskal-Wallis testi kullanılarak yapild.

\section{Bulgular}

HPLC-DAD sistemi ile propolis numunelerinde analizi yapılan 17 fenolik bileşik ve miktarları Tablo 2'de verilmiştir. 
Tablo 2. Analizi yapılan örneklerin fenolik bileşik içerikleri ve miktarları, ( $\mu \mathrm{g} / \mathrm{g}$ ham propolis)

\begin{tabular}{|c|c|c|c|c|c|c|c|c|c|c|c|c|c|c|c|c|}
\hline \multirow{2}{*}{ FenBil } & \multicolumn{14}{|c|}{ Numuneler } & \multirow{2}{*}{ Min-Max } & \multirow{2}{*}{ Ort. } \\
\hline & ŞkI & ŞkII & ŞkIII & ȘkIV & ȘkV & ȘkVI & GbI & GbII & GnI & GnII & KzI & KzII & KbI & KbI & & \\
\hline GAL & 141 & 85 & te & 60 & 147 & 118 & 709 & 245 & 88 & 131 & 109 & 93 & 10 & te & $10-709$ & $138 \pm 176$ \\
\hline EKGK & 570 & 122 & 19 & 139 & 130 & 110 & 291 & 327 & 50 & 220 & 236 & 122 & 21 & 17 & $17-570$ & $169 \pm 151$ \\
\hline KA & 2862 & 445 & 201 & 461 & 690 & 447 & 1209 & 1001 & 960 & 1155 & 580 & 1142 & 193 & 49 & $49-2862$ & $813 \pm 703$ \\
\hline FR & 887 & 758 & 14 & 125 & 266 & 157 & 7933 & 195 & 373 & 443 & 1409 & 378 & 95 & 27 & $14-7933$ & $932 \pm 2051$ \\
\hline İFR & 2864 & 682 & 19 & 431 & 717 & 346 & 13869 & 1004 & 900 & 1139 & 697 & 1041 & 140 & 31 & $19-13869$ & $1705 \pm 3571$ \\
\hline MYS & 556 & te & te & te & 83 & 33 & te & te & 134 & 176 & te & 130 & te & te & $33-556$ & $79 \pm 150$ \\
\hline DMCA & 1530 & 205 & te & 184 & 254 & 205 & te & 791 & 545 & 896 & 286 & 729 & 110 & 23 & $23-1530$ & $411 \pm 439$ \\
\hline $\mathrm{QE}$ & 2162 & 268 & 204 & 359 & 558 & 487 & te & 605 & 1665 & 2069 & 442 & 979 & 114 & 25 & $25-2162$ & $709 \pm 733$ \\
\hline $\mathrm{SA}$ & 509 & 20 & 17 & te & te & te & te & 85 & te & 240 & 103 & 221 & 33 & 13 & $13-509$ & $88 \pm 145$ \\
\hline NR & 3274 & 558 & 296 & 683 & 1133 & 572 & te & 1631 & 1485 & 1756 & 476 & 1544 & 96 & 27 & $27-3274$ & $966 \pm 906$ \\
\hline AP & 2324 & 408 & 195 & 515 & 671 & 338 & te & 802 & 993 & 1206 & 342 & 801 & 77 & 19 & $19-2324$ & $620 \pm 613$ \\
\hline $\mathrm{KF}$ & 1363 & 359 & 160 & 339 & 679 & 381 & te & 431 & 715 & 926 & 414 & 583 & 42 & 10 & $10-1363$ & $457 \pm 379$ \\
\hline CR & 5882 & 993 & 508 & 1166 & 1521 & 983 & te & 2048 & 3644 & 4584 & 805 & 2657 & 312 & 67 & $67-5882$ & $1797 \pm 1787$ \\
\hline $\mathrm{PN}$ & 18763 & 3141 & 1444 & 3275 & 4422 & 2228 & te & 4128 & 13354 & 10706 & 2335 & 6421 & 746 & 144 & $144-18763$ & $5078 \pm 5514$ \\
\hline GL & 13340 & 2044 & 857 & 3295 & 2906 & 1507 & te & 3146 & 5287 & 7053 & 2886 & 3930 & 435 & 85 & $85-13340$ & $3340 \pm 3505$ \\
\hline CAPE & 34719 & 7202 & 2977 & 8119 & 9881 & 5794 & te & 11765 & 18110 & 24562 & 5305 & 12817 & 1263 & 263 & $263-34719$ & $10198 \pm 9887$ \\
\hline $\mathrm{KL}$ & 6208 & 540 & 340 & 983 & 1079 & 558 & te & 1580 & 2768 & 2605 & 491 & 1811 & 278 & 51 & $51-6208$ & $1378 \pm 1648$ \\
\hline
\end{tabular}

FenBil: Fenolik bileşikler, GAL: Gallik asit, EGKG: Epigallokateşin gallat, KA: Kafeik asit, FR: Ferulik asit, İFR: İsoferulik asit, MYS: Metilsiringate, DMCA: 3,4-Dimetoksisinamik asit,

QE: Kuersetin, SA: Sinnamik asit, NR: Naringenin, AP: Apigenin, KF: Kaemferol, CR: Krisin, PN: Pinosembrin, GL: Galangin, CAPE: Kafeik asit fenetil ester, KL: Kalkon, ŞkI: Şemkir I,

ŞkII: Şemkir II, ŞkIII: Şemkir III, ŞkIV: Şemkir IV, ŞkV: Şemkir V, ŞkVI: Şemkir VI, GbI: Gedebey I, GbII: Gedebey II, GnI: Gence I, GnII: Gence II, KzI: Kazah I, KzII: Kazah II,

KbI: Kebele I, KbII: Kebele II. te: tespit edilemedi, Min-Max: minimum-maksimum miktarlar, Ort: ortalama değerler, \pm : Standart sapma, Ortalama değerin hesaplanmasında "te" "0" olarak değerlendirmeye alındı.

\section{Tartışma ve Sonuç}

EGKG, kafeik asit, ferulik asit ve isoferulik asit 14 propolis numunesinin tamamında (\%100); kuarsetin, naringenin, apigenin, kaemferol, krisin, pinosembrin, galangin, CAPE ve kalkon 13 (\%92.8); gallik asit ve DMCA 12 (\%85.7); sinnamik asit $10(\% 71.4)$ ve metilşiringat 7 numunede (\%50) tespit edildi (Tablo 2). Tespit edilen pinosembrin, naringenin, kuarsetin, galangin, kaemferol, kafeik asit, CAPE ve ferulik asit tespit edilme oranlarına baktığımızda Azerbaycan propolislerinin de ana kaynaklarından birinin kavak ağaçları olduğu görülmektedir. Çünkü bu fenolik bileşikler Avrupa, Asya ve Kuzey Amerika propolislerinde de yaygın olarak bulunmakta ve ana kaynak olarak, kavak ağaçları gösterilmektedir. ${ }^{6,32}$ Azerbaycan propolislerindeki tespit edilen fenolik bileşikler ve tespit edilme oranları, Azerbaycan'da Can ve ark. ${ }^{13}$ yapmış oldukları çalışma sonuçları ve
Türkiye'de yapılmış bir çalışma1 bulgularıyla genel olarak uyumludur. Volpi ve Bergonzini, ${ }^{22}$ Azerbaycan'dan temin edilen propolis numunesinde kaemferol tespit edilemediğini bildirmelerine rağmen bu çalışmada kaemferol 14 numunenin 13'de tespit edilmiştir. Bu durumun nedeni Volpi ve Bergonzini'nin yaptığ 1 çalışmada ${ }^{22}$ Azerbaycan'dan tek numune çalışmış olmalarıdır.

Analiz edilen fenolik bileşiklerin değerlendirmesini Azerbaycan ölçeğinde, yaptığımızda, gallik asit Gedebey I, EGKG Şemkir I, kafeik asit Şemkir I, ferulik asit Gedebey I, isoferulik asit Gedebey I, metilşiringat Şemkir I, DMCA Şemkir I, kuarsetin Şemkir I, sinnamik asit Şemkir I, naringenin Şemkir I, apigenin Şemkir I, kaemferol Şemkir I, krisin Şemkir I, pinosembrin Şemkir I, galangin Şemkir I, CAPE Şemkir I ve kalkon Şemkir I bölgesinde en yüksek miktarlarda tespit edildi (Tablo 2). Bu durumda Şemkir I 
nolu numunenin içerdiği fenolik bileşikler ve miktarları bakımından en kaliteli propolis olduğu; en düşük miktarlar ve dolayssiyla en kalitesiz numunenin de Kebele II nolu numune olduğu görülmektedir. Tablo 2'de görüldüğü üzere, propolislerde fenolik bileşiklerin miktarları arasında da farklılıklar bulunmaktadır. Bu durumun başlıca nedeni ise arılıkların bulunduğu bölgelerde propolis kaynaklarını içeren bitki florasının değişkenlik göstermesidir.

Tablo 3. Mevcut çalışma ile Can ve ark.13 yapmış oldukları çalışmada ortak olarak tespit edilen fenolik bileşiklerin minimum, maksimum düzeyleri ( $\mu \mathrm{g} / \mathrm{g})$.

\begin{tabular}{|c|c|c|}
\hline \multirow[b]{2}{*}{$\begin{array}{c}\text { Fenolik } \\
\text { Bileşikler }\end{array}$} & \multicolumn{2}{|c|}{ Azerbaycan propolisleri } \\
\hline & $\begin{array}{c}\text { "Mevcut Çalışma } \\
\text { Minimum-Maksimum düzeyler }\end{array}$ & $\begin{array}{c}\text { Can ve ark. } \\
\begin{array}{c}\text { Minimum-Maksimum } \\
\text { düzeyler }\end{array}\end{array}$ \\
\hline GAL & $10-709$ & $10-880$ \\
\hline EGKG & $17-570$ & - \\
\hline KA & $49-2862$ & $300-53200$ \\
\hline FR & $14-7933$ & $50-36750$ \\
\hline $\begin{array}{l}\mathbf{I F R} \\
\end{array}$ & 19-13869 & - \\
\hline MYS & $33-556$ & - \\
\hline DMCA & $23-1530$ & - \\
\hline $\mathbf{Q E}$ & $25-2162$ & $1627-69760$ \\
\hline SA & $13-509$ & - \\
\hline NR & $27-3274$ & - \\
\hline $\mathbf{A P}$ & $19-2324$ & $1770-17990$ \\
\hline KF & $10-1363$ & $1240-21590$ \\
\hline CR & $67-5882$ & - \\
\hline PN & $144-18763$ & - \\
\hline GL & $85-13340$ & - \\
\hline CAPE & $263-34719$ & - \\
\hline KL & 51-6208 & - \\
\hline
\end{tabular}

GAL: Gallik asit, EGKG: Epigallokateşin gallat, KA: Kafeik asit, FR: Ferulik asit, İFR: İsoferulik asit, MYS: Metilsiringate, DMCA: 3,4-Dimetoksisinamik asit,

QE: Kuersetin, SA: Sinnamik asit, NR: Naringenin, AP: Apigenin, KF: Kaemferol, CR: Krisin, PN: Pinosembrin, GL: Galangin, CAPE: Kafeik asit fenetil ester, KL: Kalkon,-: Çalışılmamış fenolik bileşikler,

*: Mevcut çalışma sonucu $\mu \mathrm{g} / \mathrm{g}$ ham propolis üzerinden verilmiştir.

Azerbaycan'da daha önceden Can ve ark. ${ }^{13}$ yaptığ 1 çalışmada, 15 farklı ham propolis numunesinde, analizi yapılan bireysel fenolik bileşiklerden bu çalışmada da ortak olan ve analizi yapılan gallik asit, kafeik asit, ferulik asit, kuarsetin, apigenin ve kaemferol sonuçlarını karşılaştırdığımızda (Tablo 3), tespit edilen gallik asit miktarları birbirine yakınken önceki çalışmada gallik asit iki numunede tespit edilirken bu çalışmada 12 numunede tespit edilmiştir. Kafeik asit her iki çalışmada da tüm numunelerde tespit edilmekle birlikte, önceki çalışmadaki miktarlar genel olarak daha yüksektir. Ferulik asit de her iki çalışma da tüm numunelerde tespit edilmekle birlikte yine önceki çalışmada tespit edilen miktarların daha fazla olduğu görülmektedir. Kuarsetin her iki çalışmada birer numune dışında tüm numunelerde bulunmakla birlikte önceki çalışmada daha yüksek miktarlarda bulunmuştur. Apigenin de her iki çalışmada genellikle tespit edilmiştir ancak yine önceki çalışmadaki miktarlar daha yüksektir. Kaemferol de her iki çalışmada birer numune dışında tüm numunelerde tespit edilmiş, ancak önceki çalışmadaki miktarlar daha fazla olarak tespit edilmiştir. Her iki çalışmada da yukarıda belirtilen ve ortak analizi yapılan fenolik bileşiklerde tespit edilen miktarlar Can ve ark ${ }^{13}$ yaptığ ${ }_{1}$ çalışmada genellikle daha yüksektir. Bunun nedenleri arasında propolisin toplandığı arılıkların kavak gibi propolis kaynaklarına yakınlığı, mevsim, toplama şekli, taze olarak soğuk zincirde saklanabilmesi, analiz metotları ve sonuçların değerlendirmesindeki farklılıklar sayılabilir.

$\mathrm{Bu}$ çalışma sonuçlarının ortalama düzeylerini diğer ülkelerdeki benzer çalışmaların ortalama sonuçlarıyla karşılaştırdığımızda (Tablo 4), ortalama gallik asit miktarının Türkiyedeki ortalama miktardan yüksek; kafeik asit miktarı, Türkiyede tespit edilen miktardan düşük; ferulik asit düzeyinin ise Türkiye'deki ortalama miktardan düşük olduğu görülmektedir. Kuersetin miktarı Çin, Ukrayna, Makedonya ve İtalya'daki düzeylerden yüksek olmasına rağmen, Türkiye'deki miktardan daha düşüktür. Sinnamik asit düzeyi Türkiye'deki düzeyden düşük olmakla birlikte naringenin miktarı Türkiye’de bulunan miktarla benzerlik göstermektedir. Apigenin seviyesi Çin, Arjantin, Ukrayna, Makedonya ve İtalyadaki seviyelerden yüksek olmasına rağmen Türkiye'deki seviyeden düşüktür. Kaemferol miktarının Türkiye'de bulunan miktardan biraz daha yüksek olduğu görülmektedir. Krisin düzeyleri ortalaması Ukrayna ve İtalya ortalamasından yüksek iken, Makedonya ortalaması ile benzer, Çin ve Arjantin ortalamasından düşüktür. Pinosembrin miktarları Çin, Arjantin, Ukrayna, Makedonya ve İtalya'daki seviyelerden yüksek, Türkiye'deki ortalama miktarla benzerdir. Galangin düzeyi Türkiye’de tespit edilenden düşük olmakla birlikte, Çin, Arjantin, Ukrayna, Makedonya ve İtalyadaki seviyelerden yüksektir. Bu çalışmada bulunan CAPE miktarları Türkiye, Çin, Arjantin, Ukrayna, Makedonya ve İtalya'daki miktarlardan daha yüksektir. 
Tablo 4. Bu ve benzer çalışmalarda ortak olarak tespit edilen fenolik bileşikler ve ortalama değerleri $(\mu \mathrm{g} / \mathrm{g})$.

\begin{tabular}{|c|c|c|c|c|c|c|c|}
\hline $\begin{array}{l}\text { Fenolik } \\
\text { Bileșikler }\end{array}$ & $\begin{array}{l}\text { Azerbaycan } \\
\text { (Mevcut çalışma) }\end{array}$ & Türkiye* & Çin & Arjantin & Ukrayna & Makedonya & İtalya \\
\hline GAL & 138 & $99^{(1)}$ & & & & & \\
\hline EGKG & 169 & - & - & - & - & - & - \\
\hline KA & 813 & $5014^{(1)}$ & - & - & - & - & - \\
\hline FR & 932 & $1828^{(1)}$ & - & - & - & - & - \\
\hline İFR & 1705 & - & - & - & - & - & - \\
\hline MYS & 79 & - & - & - & - & - & - \\
\hline DMCA & 411 & - & - & - & - & - & - \\
\hline $\mathbf{Q E}$ & 709 & $2746^{(1)}$ & $70^{(39)}$ & - & $28^{(39)}$ & $118^{(39)}$ & $153^{(39)}$ \\
\hline SA & 88 & $1835^{(1)}$ & - & - & - & - & - \\
\hline NR & 966 & $995^{(1)}$ & - & - & - & - & - \\
\hline $\mathbf{A P}$ & 620 & $2326^{(1)}$ & $178^{(39)}$ & $336^{(39)}$ & $177^{(39)}$ & $236^{(39)}$ & $132^{(39)}$ \\
\hline KF & 457 & $360^{(1)}$ & - & - & - & - & - \\
\hline CR & 1797 & - & $2333^{(39)}$ & $2347^{(39)}$ & $922^{(39)}$ & $1649^{(39)}$ & $781^{(39)}$ \\
\hline PN & 5078 & $4674^{(1)}$ & $2087^{(39)}$ & $3362^{(39)}$ & $1196^{(39)}$ & $2112^{(39)}$ & $769^{(39)}$ \\
\hline GL & 3340 & $4210^{(1)}$ & $1400^{(39)}$ & $2253^{(39)}$ & $952^{(39)}$ & $903^{(39)}$ & $70^{(39)}$ \\
\hline CAPE & 10198 & $2623^{(1)}$ & $2525^{(39)}$ & $1111^{(39)}$ & $1145^{(39)}$ & $1263^{(39)}$ & $1745^{(39)}$ \\
\hline KL & 1378 & - & - & - & - & - & - \\
\hline
\end{tabular}

GAL: Gallik asit, EGKG: Epigallokateşin gallat, KA: Kafeik asit, FR: Ferulik asit, İFR: İsoferulik asit, MYS: Metilsiringate, DMCA: 3,4-Dimetoksisinamik asit,

QE: Kuersetin, SA: Sinnamik asit, NR: Naringenin, AP: Apigenin, KF: Kaemferol, CR: Krisin, PN: Pinosembrin, GL: Galangin, CAPE: Kafeik asit fenetil ester, KL: Kalkon,

-: Çalışılmamış fenolik bileşikler, ${ }^{*}$ : Yaz döneminde toplanan propolislerin ortalama değerleridir.

Sonuç olarak, ham propolis analizi yapılan hedef 17 fenolik bileşikten EGKG, kafeik asit, ferulik asit ve isoferulik asit 14 propolis numunesinin tamaminda (\%100); kuarsetin, naringenin, apigenin, kaemferol, krisin, pinosembrin, galangin, CAPE ve kalkon 13 (\%92.8); gallik asit ve DMCA 12 (\%85.7) numunede, yani yüksek oranlarda tespit edilmiştir. Tespit edilen fenolik bileşikler nedeniyle Azerbaycan propolislerinin ana kaynaklarından birinin kavak ağaçları olma ihtimali yüksektir ve Avrupa, Asya ve Kuzey Amerika propolis yapısıyla benzerlik göstermektedir. Tespit edilen miktarlar pek çok ülkede tespit edilen miktarlarla genellikle benzer veya yüksektir. Analiz sonuçları bu çalışmada ham propolis üzerinden değerlendirilmiştir. Analiz sonuçları ham propolisin reçinesi üzerinden yapıldığında değerler daha da yükselecektir. Ayrıca propolis kovanlardan kazınarak toplanmıştır, propolis tuzaklarıyla taze olarak toplandığında kalitesi daha da artabilecektir. Bu nedenlerle Azerbaycan propolislerinin belirli bir kaliteye sahip olduğu; belirtilen durumlar göz önünde bulundurulduğunda ve Şemkir I gibi bölgelerden üretilen propolislerin kalitesi çok daha iyi olacağı görülmektedir. Bu nedenle Azerbay- canlı arıcı ve bilim insanlarının kaliteli ham propolis üretimi ve kaliteli propolis ürünleri üretimine önem vererek Azerbaycanlı arıcılara propolisin önemi anlatılmalı ve daha fazla ek gelir elde etmeleri sağlanmalıdır.

\section{Kaynaklar}

1. Oruç HH, Sorucu A, Ünal HH, Aydın L. Effects of season and altitude on biological active certain phenolic compounds levels and partial standardization of propolis. Ankara Üniv Vet Fak Derg. 2017a;64(1):13-20.

2. Ghisalberti EL. Propolis: A review. Bee World. 1979;60(2):59-84

3. Bankova V. Chemical diversity of propolis and the problem of standardization. J Ethnopharmacol. 2005;100(1-2):114-117

4. Mohdaly AA, Mahmoud AA, Roby HH, Smetanska I, Ramadan FM. Phenolic extract from propolis and bee pollen: Composition, antioxidant and antibacterial activities. J Food Biochem. 2015;39(5):538-547

5. Kuropatnicki A, Szliszka E, Krol W. Historical aspect of propolis research in modern times. J Evid Based 
Complementary Altern Med. 2013;11 Pages.

6. Bankova VS, De Castro SL, Marcucci MC. Propolis: Recent advances in chemistry and plant origin. Apidologie. 2000;31(1):3-16.

7. Kumova U, Korkmaz A, Avcı B Ceyran G. Önemli bir arı ürünü: Propolis. Uludag Bee J. 2002;2(2):10-23

8. Marcucci MC. Propolis: Chemical composition, biological properties and therapeutic activity. Apidologie. 1995;26(2):83-99.

9. Isla MI, Zampini IC, Ordóñez RM, et al. Effect of seasonal variations and collection form on antioxidant activity of propolis from San Juan, Argentina. J Med Food. 2009;12(6):1334-1342.

10. Toreti VC, Sato HH, Pastore GM, Park YK. Recent progress of propolis for its biological and chemical compositions and 1ts botanical origin. J Evid Based Complementary Altern Med. Volume 2013;13 Pages.

11. Sorucu A, Oruç HH. Determination of biologically active phenolic compounds in propolis by LC-MS/MS according to seasons and altitudes. J Food Meas Charact. 2019; https://doi.org/10.1007/s11694-019-001669.

12. Xu Y, Luo L, Chen B, Fu, Y. Recent development of chemical components in propolis. Frontiers of Biology in China. 2009;4(4):385-391

13. Can Z, Yıldız O, Şahin H, Asadov A, Kolaylı S. Phenolic profile and antioxidant potential of propolis from Azerbaijan. Mellifera. 2015;15(1):16-28.

14. Oruç HH, Güneş ME, Aydın L, Girişgin AO. Arı Ürünleri, Arı Sokması ve Veteriner Apiterapi. In: Doğanay A, Aydın L, ed. Bal Arısı Yetiştiriciliği, Ürünleri, Hastalıkları, 1. Baskı, Bursa, Dora Basım-Yayın Dağıtım, 2017b:153-198.

15. Barros MP, Lemos M, Maistro EL, et al. Evaluation of antiulcer activity of the main phenolic acids found in Brazilian green propolis. J Ethnopharmacol. 2008;120(3):372-377.

16. Daugsch A, Moraes CS, Fort P, Park YK. Brazilian red propolis-chemical composition and botanical origin. J Evid Based Complementary Altern Med.: eCAM. 2008;5(4):435-441.

17. Sarıkaya AO, Ulusoy E, Ozturk N, Tunçel M, Kolaylı S. Antioxidant activity and phenolic acid constituents of chestnut (castania sativa mill.) honey and propolis. J Food Biochem. 2009;33(4):470-481.

18. Huang WY, Cai YZ, Zhang Y. Natural phenolic compounds from medicinal herbs and dietary plants: potential use for cancer prevention. Nutr Cancer. 2010;62(1):1-20.

19. Aliyazıcıoğlu R, Sahin H, Erturk O, Ulusoy E, Kolayli. Properties of phenolic composition and biologi- cal activity of propolis from Turkey. Int J Food Prop. 2013;16(2):277-287.

20. Shimomura K, Sugiyama Y, Nakamura J. Component analysis of propolis collected on Jeju Island, Korea. Phytochemistry. 2013;93:222-229.

21. Nyandwi R, Ayşe SK, Çelik M, Oruç HH. Determination and quantification of gallic acid in raw propolis by highperformance liquid chromatography-diode array detector in Burundi. East Africa Science. 2019;1(1):4348.

22. Volpi N, Bergonzini G. Analysis of flavonoids from propolis by on-line HPLC-electrospray mass spectrometry. J Pharmaceut Biomed. 2006;42(3):354-361.

23. Banskota AH, Tezuka Y, Kadota S. Recent progress in pharmacological research of propolis. Phytother Res. 2001;15(7):561-571.

24. Liu R, Gao M, Yang ZH, Du GH. Pinocembrin protects rat brain against oxidation and apoptosis induced by ischemia-reperfusion both in vivo and in vitro. Brain Res. 2008;1216:104-115.

25. Cushnie TP, Lamb AJ. Antimicrobial activity of flavonoids. Int J Antimicrob Agents. 2005;26(5):343-356.

26. Long X, Fan M, Bigsby RM, Nephew KP. Apigenin inhibits antiestrogen-resistant breast cancer cell growth through estrogen receptor-A-dependent and estrogen receptor-Aindependent mechanisms. Mol Cancer Ther. 2008;7(7):2096-2108.

27. Du G, Jin L, Han X, Song Z, Zhang H, Liang W. Naringenin: a potential immunomodulator for inhibiting lung fibrosis and metastasis. Cancer Res. 2009;69(7):3205-3212.

28. Chao CL, Weng CS, Chang NC, Lin JS, Kao ST, Ho FM. Naringenin more effectively inhibits inducible nitric oxide synthase and cyclooxygenase- 2 expression inmacrophages than in microglia. Nutrition Research. 2010;30(12):858-864.

29. Calderon-Montano JM, Burgos-Moron E, Perez-Guerrero C, Lopez-Lazaro M. A review on the dietary flavonoid kaempferol. Mini-Rev Med Chem. 2011;11(4):298-344.

30. Chung TW, Moon SK, Chang YC et al. Novel and therapeutic effect of caffeic acid and caffeic acid phenyl ester on hepatocarcinoma cells: Complete regression of hepatoma growth and metastasis by dual mechanism. FASEB J. 2004;18(4):1670-1681.

31. Xiang DB, Wang D, He YJ et al. Caffeic acid phenethyl ester induces growth arrest and apoptosis of colon cancer cells via the betacatenin / T-cell factor signalling. Anticancer Drugs. 2006;17(7):753-762.

32. Velazquez C, Navarro M, Acosta A et al. Antibacterial and free-radical scavenging activities of Sonoran 
propolis. J Appl Microbiol. 2007;103(5):1747-1756.

33. Kanski J, Aksenova M, Soyanova A, Butterfield DA. Ferulic acid antioxidant protection against hydroxyl and peroxyl radical oxidation in synaptosomal and neuronal cell culture systems in vitro: structure-activity studies. J Nutr Biochem. 2002;13(5):273-281

34. Sova M. Antioxidant and antimicrobial activities of cinnamic acid derivatives. Mini-Rev Med Chem. 2012;12(8):749-767.

35. Raina K, Rajamanickam S, Deep G, Singh M, Agarwal R, Agarwal C. Chemopreventive effects of oral gallic acid feeding on tumor growth and progression in TRAMP mice. Mol Cancer Ther. 2008;7(5):1258-1267.

36. Erdogan S, Ates B, Durmaz G, Yilmaz I, Seckin T. Pressurized liquid extraction of phenolic compounds from Anatolia propolis and their radical scavenging capacities. Food Chem Toxicol. 2011;49(7):1592-1597.

37. Trusheva B, Trunkova D, Bankova V. Different extraction methods of biologically active components from propolis: A preliminary study. Chem Cent J. 2007;7:1-13.

38. Pellati F, Orlandini G, Pinetti D, Benvenuti S. HPLCDAD and HPLC-ESI-MS/MS methods for metabolite profiling of propolis extracts. J Pharmaceut Biomed. 2011;55(5):934-48.

39. Medana C, Carbone F, Aigotti R, Appendino G, Baiocchi C. Selective analysis of phenolic compounds in propolis by HPLC- MS/MS. Phytochem Anal. 2008;19(1):32-39. 